\title{
Transformation Mechanism of a Fault and Its Associated Microstructures in Low-Porosity Rocks: A Case Study of the Tanan Depression in the Hailar-Tamtsag Basin
}

\author{
Ru Jia ${ }^{1,2,3}$, Bo Liu ${ }^{1,2,3, *}$, Xiaofei Fu ${ }^{1,2,3}$, Lei Gong ${ }^{1,2,3}$ and Zhida Liu ${ }^{1,2,3}$ \\ 1 Key Laboratory of Continental Shale Hydrocarbon Accumulation and Efficient Development (Northeast \\ Petroleum University), Ministry of Education, Northeast Petroleum University, Daqing 163318, China \\ 2 Laboratory of CNPC Fault Controlling Reservoir, Northeast Petroleum University, Daqing 163318, China \\ 3 Science and Technology Innovation Team in Heilongjiang Province "Fault Deformation, Sealing and Fluid \\ Migration", Northeast Petroleum University, Daqing 163318, China \\ * Correspondence: liubo6869@163.com; Tel.: +86-0459-6504095
}

Received: 1 August 2019; Accepted: 21 August 2019; Published: 24 August 2019

\begin{abstract}
Faults have complex internal structures, which can be divided into the fault core and the damaged zone. During the fault formation process, the damaged zone will develop a large number of fractures cross cutting the adjacent host rocks, where the size and density of fractures would decrease as a function of distance from the fault core. Statistics show that compared with the host rocks, the rock's secondary porosity may significantly get improved until it is $5 \%-10 \%$ higher than the host rock's, and the permeability could be increased from zero to six orders of magnitude higher where fractures are developed. Based on the distribution of the fault core and damaged zone, we established an idealized geologic model to analyze the influence of the fault associated microstructures on the fluid flow efficiency. The results demonstrated that the reservoir property will be effectively improved when the fractures are developed to a certain magnitude, which will provide an advantageous conduit for fluid flow. The physical properties of wells are significantly different between the reservoirs transformed by the fractures and the reservoirs that have not been affected. The reservoir unit near faults has been modified by the associated fractures improving the reservoir quality. In addition, the portions of the reservoir farther from the fault core are less influenced and retain their initial poor characteristics. In order to evaluate the enhanced reservoir properties caused by faults and associated fractures, we performed statistical analysis of valid porosity ratio of the Nantun reservoirs as a function of the distance from 49 wells to faults in the research area. The results of this study demonstrated that connected fractures enhance the properties of the reservoirs and there is a distinct range that separates oil producing wells and water producing ones. This phenomenon verifies that faults are important and must be considered carefully during the exploration and production for hydrocarbon to provide higher quality reservoirs.
\end{abstract}

Keywords: low porosity rock; fault deformation; damage zone; fracture; fluid flow

\section{Introduction}

Fault zones are the main products of diastrophic activity, and they play an important role in rock mass deformation and fluid flow. In petroleum exploration and development, faults can become migration pathways, barriers or a combination of both. The presence of faults increases the risk factors associated with hydrocarbon drilling, exploration, and production. Previous research including structural and micro-structural analyses of cores, outcrop samples, well bores, and production data have 
been used to evaluate the fault zones and their internal micro-structures in hydrocarbon accumulation and production.

At sub-seismic resolutions, faults are generally defined as planes or surfaces with shear displacement discontinuities [1-4]. Whereas, most faults have a certain thickness and exhibit typical binary structures that consist of fault core and damaged zone [5-7]. Fault cores are shear bands that may include slip surfaces, tectonic lenticles, and fault rocks (fault gouge, fault breccia, cataclastic rocks, and shale smear) [5,8-12]. The thickness of fault core generally varies with the amount of fault displacement, from a few centimeters for sub-seismic faults to several meters for kilometer-scale faults. The damaged zone is a network of subsidiary structures (secondary faults, fractures, deformation bands, and dikes) that bound the fault core and may alter the permeability relative to the fault core and the undeformed host rocks. Kim (2004) divided damaged zones into tip damaged zones, wall damaged zones, and linking damaged zones, based on position within and around a fault plane. According to the differences in the properties of the rocks, particularly damaged zones, and host rocks, faults can be divided into two categories. The first category occurs in low porosity rocks, where deformation produces fault breccias and gouges in fault core, and a large number of fractures are developed in the damaged zone. The density of fractures will progressively decrease with increasing distance from the fault [7]. When the fracture density is consistent with the host rock's fracture density, the damaged zone terminates. The second category happens when a fault develops in porous rocks (porosity is greater than $15 \%$ ), that produces cataclastic rocks, and deformation bands are developed in damaged zones, that are formed by particles sliding or rotating and by particles being damaged by local compaction, expansion, or shearing [4,13-21]. Similar to the distribution characteristics of the fractures, the density of the deformation bands decreases with increasing distance from the fault, and the damaged zone will terminate when the density of fractures is the same as the host rocks [22,23].

The damaged zone and its microstructures represent a petrophysical anomaly belt in the reservoir rock compared to the host rock because the microstructures alter the properties of the rocks. In general, deformation bands are found in most siliciclastic sandstone reservoirs where they tend to have lower permeability than the host rocks $[15,17,24-26]$. Thus, they are considered by many to prevent the flow of fluids during oil migration [25-31]. In contrast, fractured reservoirs appear to have better petrophysical properties than host rocks when the fractures are opened. Conversely, once the fractures have been closed or cemented, they will no longer improve the reservoir's petrophysical properties. The interconnected fractures usually form the fluid migration channel [32-34].

The displacement and thickness of fault zones are generally positively correlated [35-37]. This represents a growth trend, i.e., a small fault will gradually broaden with increasing displacement $[36,38,39]$. Childs et al. (2009) showed that the damaged zone around a fault can reach approximately $1000 \mathrm{~m}$ when the fault has a $100 \mathrm{~m}$ displacement, which indicates that a large number of microstructures are developed in the fault trap and the reservoir has been strongly altered.

Unconventional oil and gas reservoirs have become the primary focus of the energy industry, but great challenges facing oil and gas exploration and development in China. Faults in low porosity reservoirs are the main factor in oil production, through transforming reservoir quality. Therefore, efforts to identify high quality reservoirs and guidelines for more efficient exploration and development of such petroleum traps should be established. Although the importance, in practice, proving that faults and their associated microstructures have a significant influence on fluid flow in petroleum reservoirs is difficult. This is related to our limited knowledge of sub-seismic structures within low porosity reservoirs. Such as where these microstructures are developed and what their petrophysical properties are. Are they distributed and arranged in a regular pattern? How much do they contribute to the hydrocarbon migration?

In this paper, we will use the Nantun Formation sandstones in the Tanan Depression of the Hailar-Tamtsag Basin as an example to investigate the mechanisms of fault deformation in low-porosity reservoirs, to investigate the regularities in distribution of microstructures, and the types of microstructures associated with faults. Furthermore, their transforming effect on low-porosity 
reservoirs based on field observation, petrophysical characteristics of wells, mathematical calculations, and fluid-flow simulations are presented as well. This study will provide us some insight into the role of faults in enhancing reservoir quality and flow in a major sandstone formation and a source of hydrocarbons in China.

\section{Geologic Setting}

The Tamtsag Basin is located in the eastern part of Mongolia, and extends to the northeast into China. It belongs to the same basin as Halaer Basin in northern China; where they have a uniform tectonic setting and basin evolution process [40-44]. The Hailar-Tamtsag Basin is a Meso-Cenozoic continental rifted basin superimposed on the Mongolia-Hinggan orogenic belt $[40,45,46]$. It has experienced five periods of evolution: the residual basin period, the initial rifting period, the intense rifting period, the fault-depression transformation period, and the post-rifting period [45].

The Tanan Depression is a NE-trending secondary tectonic unit of the basin that is faulted to the east and overlaps the Tamtsag Basin to the west [45,47-49]. The depression is mainly composed of a series of half-graben depressions controlled by a NE-dipping normal fault. It can be divided into the western slope, western sub-sag, western buried-hill faulted zone, central sub-sag, central buried-hill faulted zone, eastern sub-sag, and eastern fault nose [50,51] (Figure 1).
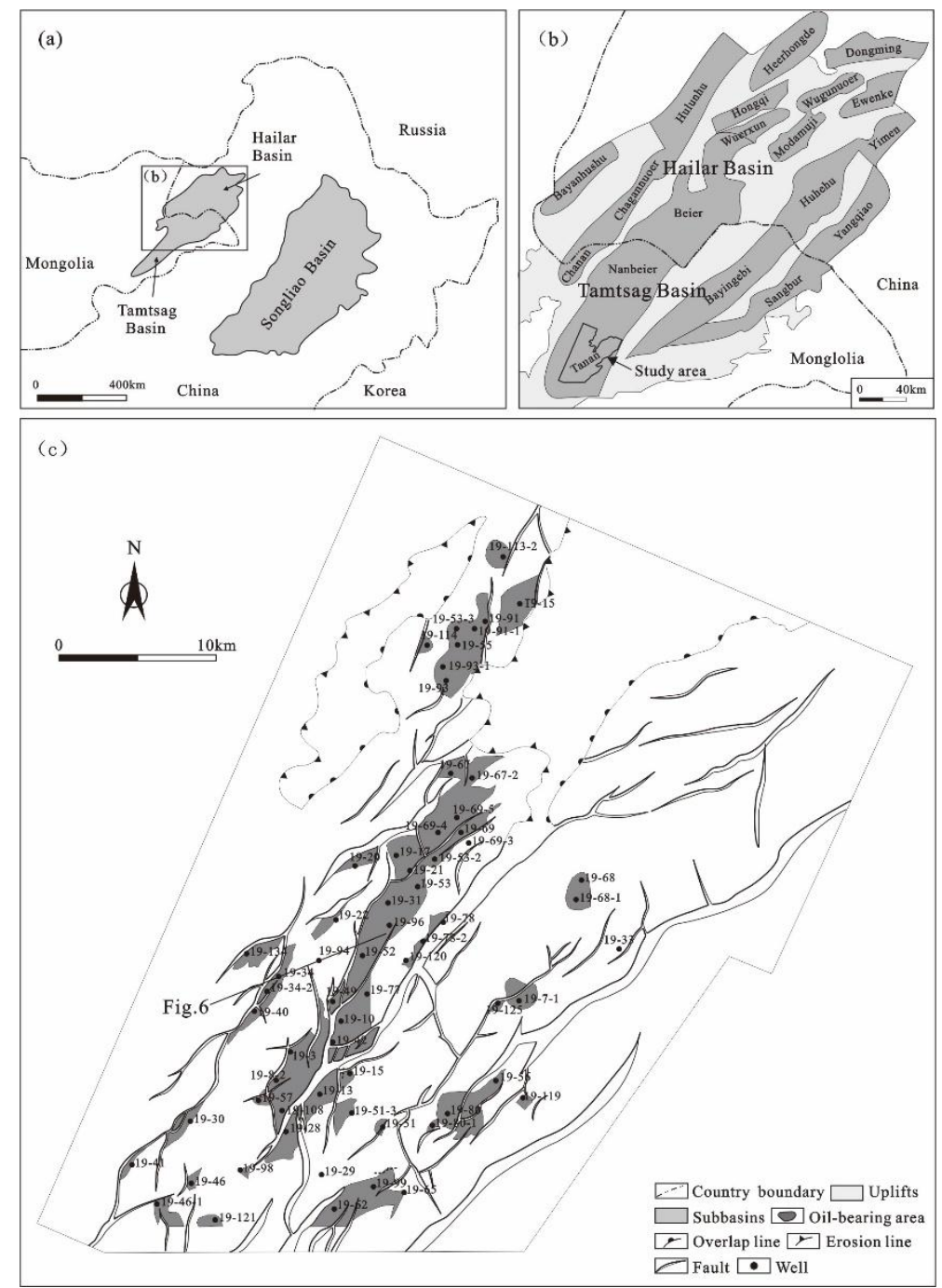

Figure 1. Geographical map and structural outline of the Tanan Depression. (a) The basin location in China. (b) The study area and tectonic units of Hailar-Tamtsag Basin. (c) The faults, well locations and oil-bearing area in Tanan Depression. 
The Jurassic-Cretaceous system is the main sedimentary body in depression, the strata in the depression are divided into the Lower Cretaceous basement, TongBomiao, Nantun, Damoguaihe, and Yimin Formations, and the upper Cretaceous, Palaeogene, and Neogene Qingyuangang Formation (Figure 2). The depression underwent multi-stage tectonic deformation in the initial rifting period, which is equivalent to the deposition period of Tongbomiao Formation. In this stage faults began to form, but the size of faults and the throws were not large, which formed an obvious uplift and erosion that resulted in $\mathrm{T}_{3}$ angular unconformity. Subsequently, the depression entered the intense rifting period, while with the strong fault activity, fault size and fault throw significantly increased. Finally, at the end of this period, tectonic uplift made partial truncated unconformity in the $T_{22}$ interface $[51,52]$. In Damoguaihe Formation and early-middle Yimin Formation, only a few faults were active, then strong tectonic deformation occurred again in the end of Yimin Formation, that led to the reactivation of rift faults and then formed new faults.

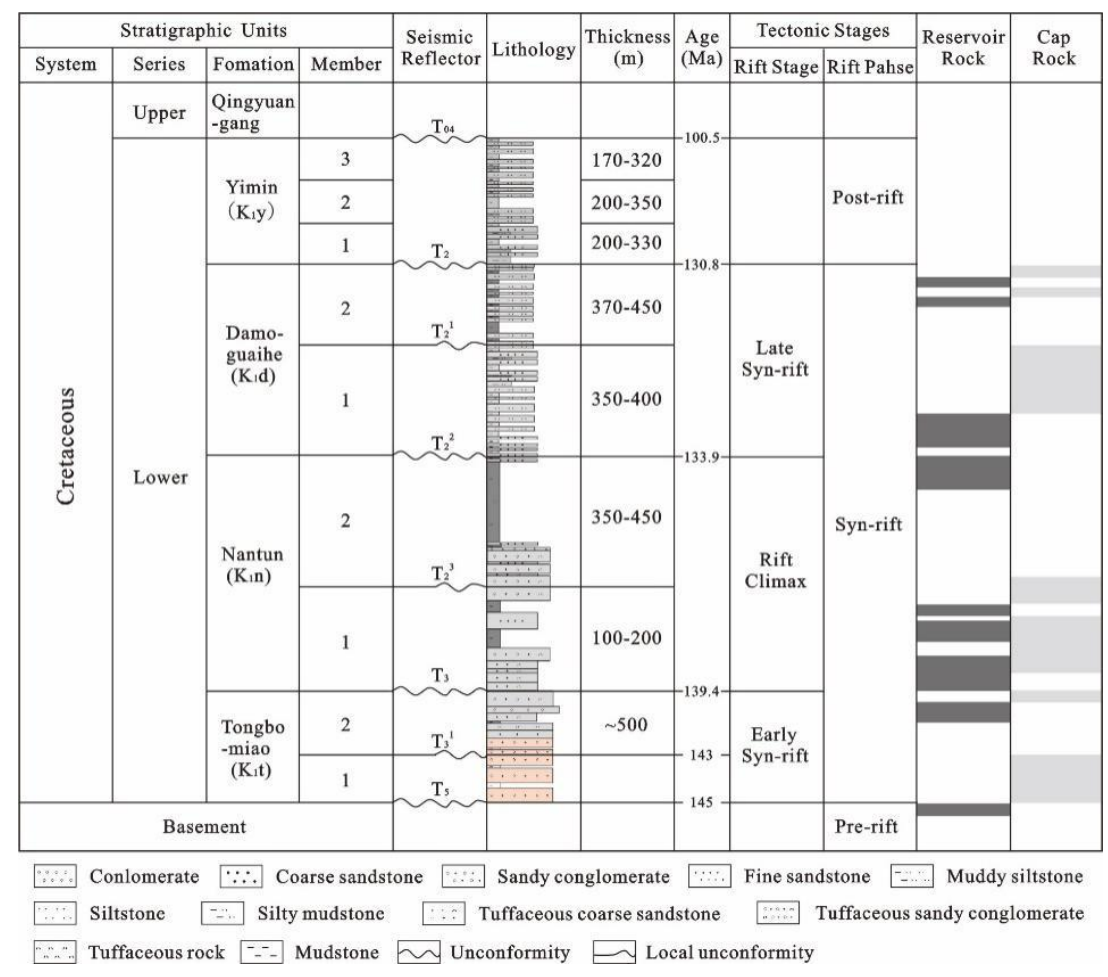

Figure 2. The comprehensive stratigraphic column of the Tanan Depression.

The hydrocarbons in the depression are mainly distributed in the formations during the rifting period. The research area has two sets of regional caprocks, namely, the argillaceous rocks (contain the tuff) in the upper of Nantun Formation and the argillaceous rocks in the Damoguaihe Formations. The complicated tectonic framework of the Tanan Depression controls the provenance and orientation of the lithologic bodies, resulting in high sedimentation and unloading rates. The reservoir's thickness, lithology, physical properties, and sedimentary facies vary throughout this area. The basin has abundant low porosity reservoirs, which have undergone commercial oil and gas development. These reservoirs are located in the basement, the Tongbomiao Formation, Nantun Formation, and Damoguaihe Formation. The oil and gas mainly come from the source rocks in the upper and middle of first member of Nantun Formation.

The main focus of this study is the first member of the Nantun Formation. In this period, the lake basin expanded and deepened, resulting in a change in the sedimentary environment. The depression developed a relatively complete depositional system including lowstand, lacustrine transgressive, and highstand system tracts [53]. Some near provenance fans developed, and distribution of superposition vertically, which is the main oil and gas bearing reservoir unit in the area and contains complex 
polycyclic lithologic intervals of interbedded sandstone and mudstone. The reservoirs are generally coarse-grained and poorly sorted, and the pores are mainly secondary pores such as intergranular dissolved pores. The oil shales, argillaceous limestones, and black mudstones at the top of the first member of the Nantun Formation are the main source rocks. They are 150-450 m thick and the hydrocarbon-generation area is greater than $700 \mathrm{~km}^{2}$. This dense layer forms an effective seal for the oil and gas.

\section{The Fault Deformation Mechanism and Associated Microstructures}

\subsection{Fault Deformation Mechanism}

The factors influencing the fault deformation mechanisms are both internally generated (lithology, mineral content, diagenetic stage, porosity, and permeability) and externally generated (temperature, pressure, and deformation depth) [20,54]. Previous studies have concluded that significant brittle deformation occurs in sandstone with porosity greater than $15 \%$ when the normalized confining pressure is less than $0.25 \mathrm{MPa}$ and the fault permeability is constant or slightly reduced. When the normalized confining pressure is greater than $0.25 \mathrm{MPa}$, the sandstone is in the brittle-plastic transition stage and the fault permeability is significantly decreased. When the normalized confining pressure is less than $0.25 \mathrm{MPa}$ and the porosity is less than $15 \%$, the sandstone undergoes significant brittle deformation and fault permeability increases. Therefore, porosity of $15 \%$ is considered as the threshold between high porosity and low porosity zones in the sandstone [20]. Based on the porosity of the rocks, they can be divided into three groups. The first is high porosity rock, which Fisher et al. (2003) classified as having porosity greater than $15 \%$. These include several different types of sandstones. The second is low porosity rocks, which have a porosity of less than $15 \%$ and mostly include conglomerate, sandstone, and argillaceous rocks in the over-consolidated diagenetic stage. The third is non-porous rocks, which usually have a porosity of less than $5 \%$, such as carbonate rocks, volcanic rocks, and metamorphic rocks. However, not all deformations are brittle. Carbonates and silicalites are generally brittle rocks. Sulfates and halides are brittle in the shallow burial period, but they are generally plastic after deep burial. Volcanic rocks in the invasion and eruption phases are in a molten state, so fault deformation does not usually form a clear fault zone in these rocks.

Rawling et al. (2003) concluded that during the early solidification stage, high porosity sandstone has an granular/particulate flow deformation mechanism, which is caused by particles rotating and rolling during grain-boundary frictional sliding. This results in the rearrangement of particles to form disaggregation bands $[55,56]$. The disaggregation zone can be further divided into the dilational band and compressive band. The dilational band is related to abnormally high pore fluid pressures, which is characterized by an increase in volume, and the porosity and permeability being significantly increased. In contrast, the compressive band has relatively poor properties compared to the host rocks. The disaggregation zone has little effect on the reservoir properties and some disaggregation zones become channels for the vertical fluid migration. In the post-solidification stage, the mechanism of fault deformation is cataclasis, which occurs when the frictional sliding of grain boundaries causes the grains to rotate and roll, resulting in the cataclastic flow and forming the cataclastic bands [14,20,57-59] (Figure 3a). Cataclastic bands widely develop in the damaged zone and have mineral composition similar to the host rocks. The grain size of the bands decreases to microscopic sizes and the sorting becomes poor. The thickness of a single cataclastic band is few millimeters and they are inhomogeneous along the strike and dip. The thickness of a cataclastic band cluster can be as large as few centimeters or few decimeters. 

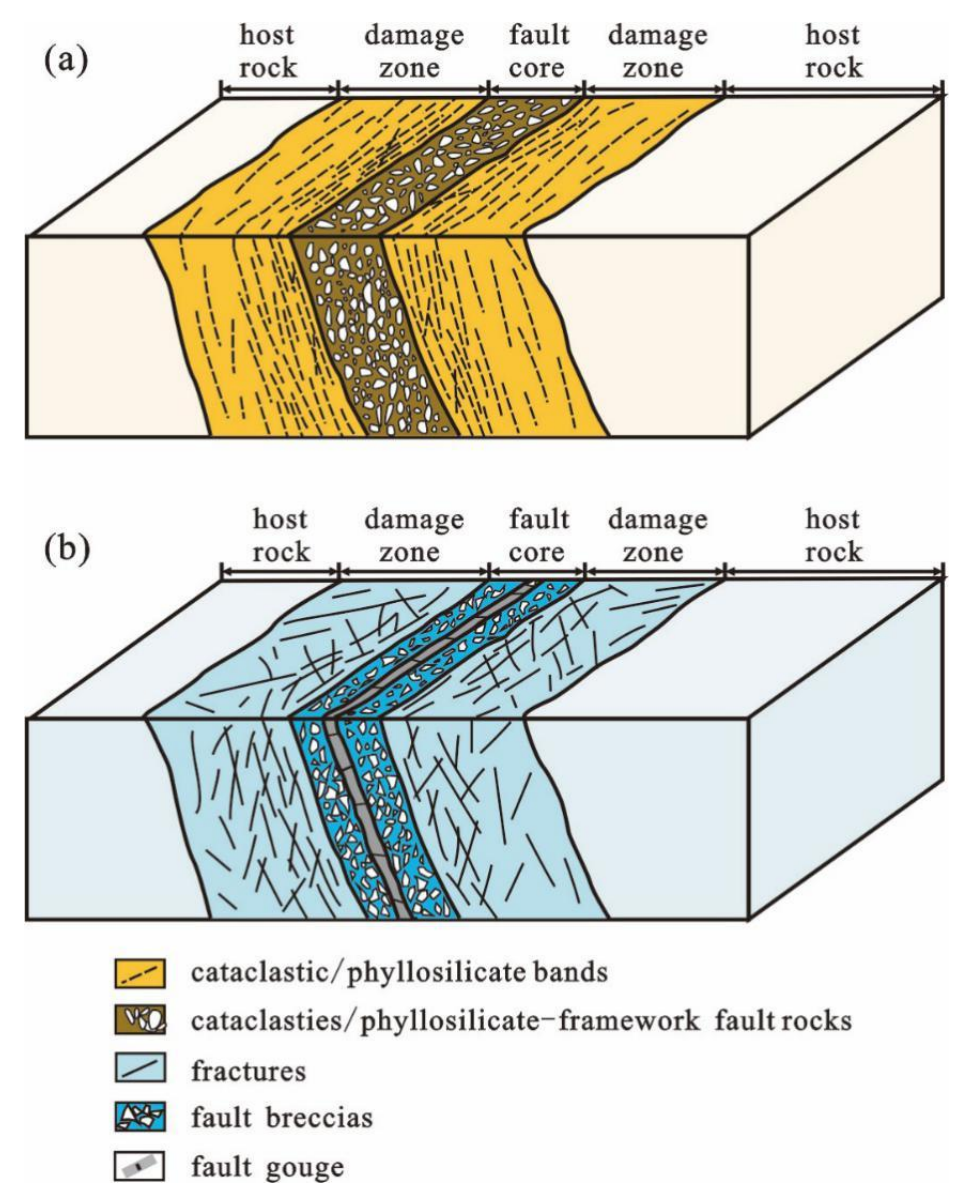

Figure 3. The pattern of fault zones in consolidation diagenesis reservoirs, (a) porous reservoirs, and (b) non-porous to low porosity reservoirs.

The mechanisms of fault deformation in low porosity and non-porous rocks is different from that in porous rocks. The mechanism of fault deformation in low porosity rocks is fracturing when the burial depth is less than $3 \mathrm{~km}$, which results in the generation of many intragranular cracks in the rocks, forming the incoherent fault breccia and fault gouge. In general, this fault zone is characterized by "inflation", i.e., the permeability increases with the generation and opening of fractures [20,54]. As the fractures develop further, at a burial depth of greater than $3 \mathrm{~km}$, frictional sliding occurs along the fractures as the broken granules roll, resulting in cataclastic flow deformation forming fault gouge, cohesion fault breccias, and cataclastic rocks (Figure 3b). In particular, the fault gouge zone has relatively lower permeability. Due to the relaxation and release of stresses [4,54], the deformation of the fault in the lifting stage after the consolidation diagenetic stage produces large numbers of fractures, creating a fault core that consists of incoherent fault breccias and fault gouge, which is a permeable fault zone. In addition, the overpressure and temperature also have a certain impact on the fault deformation. The effect of the confining pressure decreases with the injection of overpressure fluid along the fault zone, even though the deformation depth is still deep. This will cause an expansion in the fault breccias. In tight sandstones, the deformation of the fault zone leads to quartz pressolution-cementation and forms a sealing fault zone when the geothermal temperature is higher than $90^{\circ} \mathrm{C}$. One of the important factors determining whether low porosity rocks can serve as an effective reservoir is the degree of development in the damaged zone.

\subsection{Fault Associated Microstructures}

Microstructures formed by the deformation of high porosity rocks in the deformation zone, can be divided into three categories: the disaggregation band, the cataclastic band, 
and the pressolution-cementation cataclastic band in the early solidification, post-solidification, and over-consoildated diagenetic stage, respectively [14,20,26,54-59]. The appearance of the disaggregation bands usually would have lighter color than the host rocks and the particle size has no obvious change in the bands. Due to the rotation and rolling of the particles, the particles show obvious directional arrangement and their porosity and permeability have minor changes compared to the host rocks. Cataclastic bands are formed in a variety of tectonic environments, and their appearance is usually rib form. On the micro level, it can be seen that the size of particles decreases, the sorting becomes worse, and the porosity and other physical properties are significantly inferior than the host rocks. When depth of burial is more than $3 \mathrm{~km}$, the subsurface temperature would be more than $90^{\circ} \mathrm{C}$, and the quartz pressolution would occur in the cataclastic bands and form the solution bands.

Fault deformation in low porosity rocks is less affected by the diagenetic stage. The deformation structures in the shear zone are primarily fractures [60,61], such as extensional, shearing, and pressolution fractures [4], with micro-fracture connections and macro-fracture reactivation that leads to the formation and propagation of the fault [62]. The regulation of fracture development in the shear zone conforms to the Riedel theory; fractures cut through the rock creating fault breccias, and with continual shearing, faulted breccia is gradually transformed into a fault breccia induced fault gouge [63]. The stress field on both sides of the fault is produced by the primary fault derived fractures cutting the host rock, thus forming the damaged zone [5]. Regardless of cementation and diagenesis, the damaged zone has a higher permeability than the host rocks because of the existence of fractures. The fractures in the damaged zone generally have the following characteristics: (1) the density of fractures will progressively decrease with increasing distance from the fault core. When the fracture density tends to be consistent with the regional fracture density, it marks the termination of the damage zone; (2) according to differences in fracture development in the two plates, the damaged zone can be divided into two types: symmetrical and asymmetrical. In a symmetrical damaged zone, the density and size of fractures are the same on both plates. In an asymmetrical damaged zone, the fracture density is larger and wider in the hanging wall than in the footwall. Most damaged zones observed in our field investigation were asymmetrical; and (3) there are differences in the degree of development of the fractures in the plastic strata compared to the brittle strata. Fractures in the brittle strata are developed within a wide damaged zone, while in the plastic strata the fractures are not well developed, and most of them are small folds and drag structures.

The first member of the Nantun Formation is the main reservoir in the Tanan Depression. The reservoir lithology is mainly lithic sandstone [51], with a low porosity of $5 \%-20 \%$ and poorly connected pore space resulting in permeability of less than $10 \mathrm{mD}$, making it a low-medium porosity and ultra-low permeability reservoir $[43,45,47,51]$. The reservoir belongs to stage $\mathrm{A}$ of the middle diagenesis phase, the burial depth of which is generally less than $3 \mathrm{~km}$. According to the fault deformation law, the fault core should develop incoherent fault breccia and fault gouge, and the damaged zone should develop numerous fractures.

Field studies in Hulunbeier City are used in this paper to investigate the fault zone and associated fractures in the Tanan Depression. The outcrop is located on the southwestern side of a road that is $1 \mathrm{~km}$ from Human Highway in Hulunbeier City. The outcrop contains dark grey silty mudstone and tuffaceous sandstone of the Nantun Formation with a sand-shale ratio of more than $54.8 \%$. The exposed fault throw observed in the sandstone is about $0.7 \mathrm{~m}$ (Figure $4 \mathrm{a}$ ). The fault core is filled with a large amount of fault breccia interspersed with host rocks with a maximum thickness of $40 \mathrm{~cm}$ (Figure $4 \mathrm{c}$ ). Sampling analysis shows that there is no cohesive force within the fault breccia and the percentage of fault rock in the core is extremely low, indicating lack of fault ability to lithify into a cohesive unit. In addition, on both sides of the fault, many fractures have developed in the host rock adjacent to the fault and the density of the fractures decreases gradually with increasing distance from the fault core (Figure 4d). 


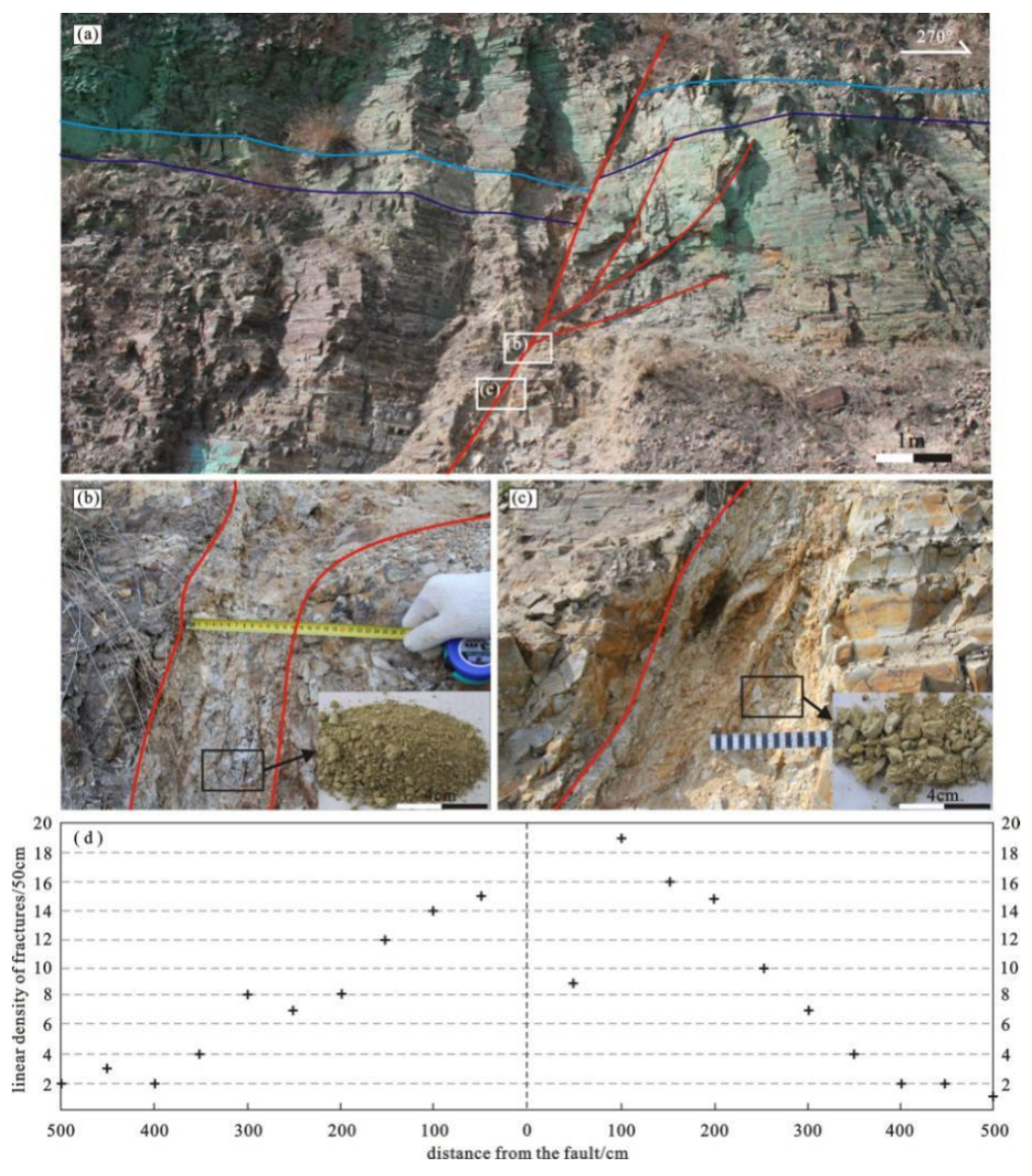

Figure 4. The field profile of the Nantun Formation in the Tanan Depression, (a) the exposed fault in the field, $(\mathbf{b}, \mathbf{c})$ fault core with fault breccia, and (d) the density of fractures in the damage zone.

\section{Fractures and Their Influence on Fluid Flow}

\subsection{Petrophysical Properties of Fault Zones}

Fault zones are composed of fault core and damaged zone. In low porosity rocks, the fault core is composed of the incoherent fault breccias, cohesive breccias, cataclasites, gouge, structural lenses, and sliding surfaces. The fault's damaged zone develops numerous fractures, which are often defined as anomalous areas of petrophysical properties because of the post-depositional alterations of the rocks. Studies show that the porosity of the incoherent fault breccia is $2 \%-5 \%$ higher than the host rocks, and the permeability is $1-4$ orders of magnitude higher [52,64]. The porosity of the more deformed part of the damaged zone is $5 \%-6 \%$ higher than the host rocks, and the permeability is $4-6$ orders of magnitude higher. The porosity in the less deformed part of the damaged zone is $2 \%-6 \%$ higher than the host rocks and the permeability is $1-6$ orders of magnitude higher. When the deformation depth exceeds $3 \mathrm{~km}$, the damaged zone will develop cohesive cataclastic rocks and ultracataclasite, which have higher porosity and permeability than the host rocks $[52,64]$.

Up to date, most literature has focused on the effect of the fractures on reservoir quality, but little attention has been paid to the controlling effects of fractures on fluid flow. In this paper, the influence of the fractures on the fluid flow efficiency is calculated using the formula deduced from the mathematical theory described in the following section.

\subsection{Mathematical Modeling and Result}

The highest concentrations of deformation in faulted low porosity rocks occur in the fault damaged zone close to the fault core. We will consider here a simple but realistic example that includes 
a producer and injector (Figure 5) based on a mathematical framework describing linear, single phase flow in non-porous to low porosity rocks with fractures. This model cannot exactly represent the real production status of existing wells because well production depends on several variables that are not considered here, such as stratigraphic thickness, characteristics of faults, and well conditions. Though, the purpose of our model here is simply to highlight the fractional increase in productivity as a result of increased average permeability between the injector and producer, which is caused by the presence of fractures. Therefore, the results of our modeling is not an exact representation of the field but sufficient for the purposes of this study.

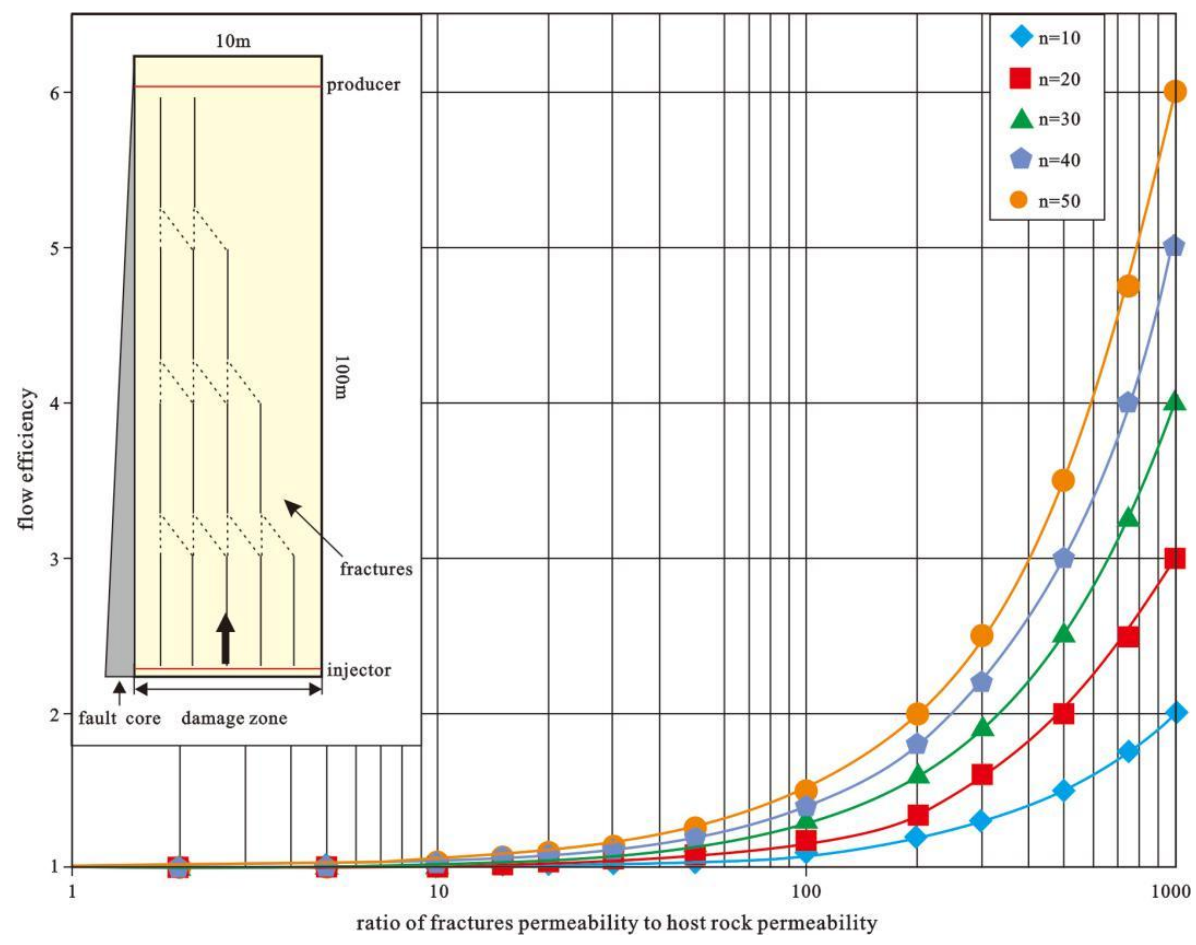

Figure 5. Relationship between the ratio of fractures to host rock permeability and fluid flow efficiency in low porosity rocks.

In our simplified model, Figure 5 represents a typical low porosity sandstone reservoir with a horizontal injector placed $100 \mathrm{~m}$ from a fault at the boundary of the damaged zone and a producer placed very close to the fault core. The width of the model is $10 \mathrm{~m}$. A large number of fractures are distributed between the injector and producer. The pristine, low porosity host sandstone is taken to be $1 \mathrm{mD}$. We assume that the flow is linear, and the fractures are infinitely long, extending across the entire sandstone layer with constant thickness and other properties with an average thickness of about $1 \mathrm{~mm}$.

The influence of fractures on fluid flow depends on the number of fractures and permeability of the damage zoned. Thus, flow efficiency (FE) was calculated with trial and error of using different values for permeability of fractures in the damaged zone, calculated as $Q_{d} / Q_{p}$. In this model $Q_{d}$ and $Q_{p}$ are the fluid discharge of the host rocks with fractures and the primary host rock without any fractures, respectively. $Q$ is calculated using Darcy's law as follows:

$$
Q=K A \frac{H_{1}-H_{2}}{L}=K A I
$$

where $Q$ is the flow discharge, $K$ is the permeability, $A$ is the cross-sectional area, $H_{1}$ and $H_{2}$ is water head, $L$ is the fluid flow length, and $I$ is the pressure gradient. $K$ is calculated as follows:

$$
K=\frac{\rho g}{\mu} k
$$


where $k$ is the permeability, $\rho$ is the liquid density, $g$ is the gravitational acceleration, and $\mu$ is the viscosity. $K$ is positively correlated with the permeability $k$.

The flow efficiency is the ratio of the fluid discharge in the deformed reservoir with fractures to the fluid discharge in the primary reservoir without any fractures. This ratio can be calculated as follows:

$$
\frac{Q_{d}}{Q_{p}}=\frac{n k_{f} A_{f}+k_{h}\left(A_{h}-n A_{f}\right)}{k_{h} A_{h}}
$$

where $Q_{d}$ is the fluid discharge in the deformed reservoir with fractures, $Q_{p}$ is the fluid discharge in the primary reservoir without fractures, $n$ is the number of fractures, $k_{f}$ is the permeability of the fractures, $k_{h}$ is the permeability of the host rocks, $A_{f}$ is the cross-sectional area of the fractures, and $A_{h}$ is the cross-sectional area of the host rocks without fractures.

Figure 5 is a dimensionless plot where the rising tendency of flow efficiency is related to the ratio of fracture permeability to host rock permeability. Although the model shows different numbers of fractures, the mathematical calculation is independent of the internal position and distribution of the fractures. Reservoir permeability is the joint contribution of host rock permeability and fracture permeability. The results show that the flow efficiency is more significantly increased when the permeability of the fractures in the damaged zone is two orders of magnitude higher than the host rocks $\left(k_{f} / f_{h}>100\right)$ (Figure 5). For the $k_{f} / f_{h}=100$, the enhanced flow efficiency can be seen to be 1.5 when the number of fractures reaches 50 . As the permeability ratio increases, the flow efficiency increases too. This phenomenon indicates that the fractures have a significant effect on the fluid flow in low porosity reservoirs.

\section{Discussion}

\subsection{Limitations of the Mathematical Modeling}

As mentioned above, we showed that the fractures in the damaged zone effectively would enhance fluid flow in the reservoir, and we used our mathematical model to calculate the fluid flow efficiency of the fractures in low porosity rocks. The fractures in the model have higher permeabilities than the host rock, and their distributions are uniform and their cumulative thickness is higher than what was observed in the field. It should be emphasized that the model presented here is based on single-phase fluid flow and under simplified conditions, which means that the conclusions cannot be used for two-phase or multi-phase fluid systems.

Regardless of the complications caused by multi-phase flow, we demonstrated that fractures significantly increase permeability when a good number of fractures reach a certain size, and they can contribute to hydrocarbon migration. However, the limited connectivity of these fractures can have counter effects. In theory, we focused on fractures subparallel to the fault, which will serve as channels for hydrocarbon flow while field studies [65] and core analyses [28] show that microstructure orientations can be very complex, and those subparallel to the fault or conjugate directions tend to dominate. However, it should be noted that individual fractures have little impact on the effective permeability of the reservoir. They only could have an effect when fractures with various orientations are connected, causing the permeability to increase 10-1000 times than the host rock [66]. Hence, the three-dimensional connectivity of these fractures is the limiting factor on fluid flow efficiency. The degree of development and connectivity of the fractures not only influence the seepage of fluids in the fractures, but also play an important role in maintaining high and stable production, reservoir protection, and in enhancing the reservoir's properties. Fractures have been found in most if not every faulted low porosity reservoir where cores were available for inspection. In Xujiaweizi Depression of Songliao Basin, thousands of fractures are identified in cores and outcrops, basically all located in the fault zones [23]. Micrographs and other petrophysical information from the cores prove that fractures enhanced reservoir storage space and fluid flow properties [23]. 
Although the model has some limitations, it can support our views to a certain extent. To further demonstrate the transformation of fractures on low porosity reservoirs, we selected reservoir physical properties data from two representative wells (Figure 6). This data was all derived from the cores (Table 1). The first well is shown as well 19-34 in Figure 6e, located adjacent to the fault, and the second one is well 19-94 in Figure 6e which is located far from the fault. Through comparison of well data (Figure 6a-d), a major discrepancy in petrophysical properties of the wells are found. The reservoirs near the fault show deformation characteristics from the resultant fractures, which has enhanced reservoir quality. Whereas, the reservoir units farther from the fault show a little deformation and the host rock retains its poor properties (Figure 6a-d).
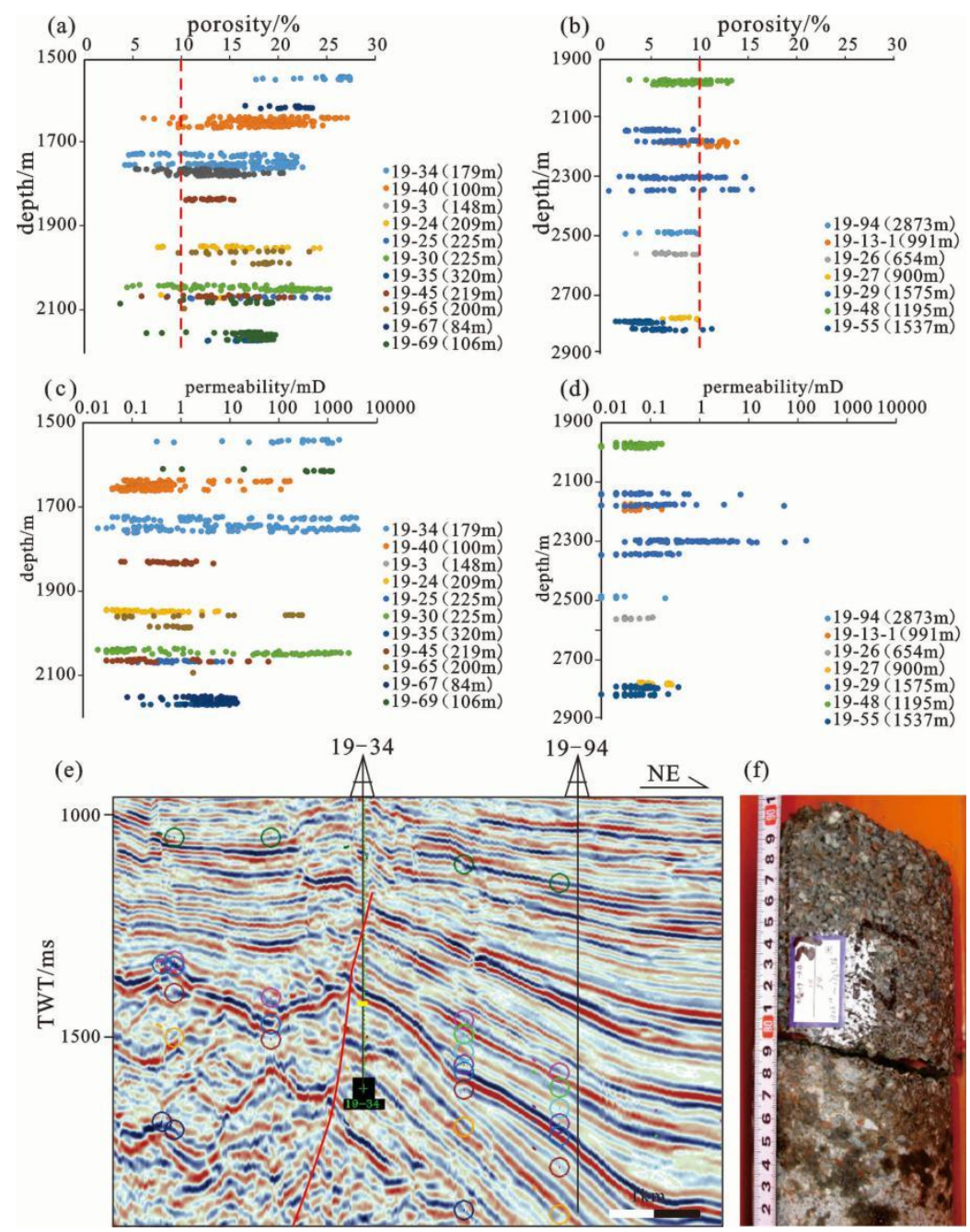

Figure 6. Comparison of the properties of reservoirs in the Tanan Depression, $(\mathbf{a}, \mathbf{b})$ are the reservoir porosities in the two types of wells one close to the fault and altered by fractures and the other one far from the fault with the same quality as the host rock, and (c,d) are the reservoir permeabilities that correspond to experimental points in figure $(\mathbf{a}, \mathbf{b})$, respectively. The colored dots are measured porosities and permeabilities in individual wells. Numbers i.e., 19-34 represent the well number and the number in parenthesis (i.e., $179 \mathrm{~m}$ ) is the distance from the faults; (e) is the typical seismic profile of oil trap to show the position of the two types of wells with respect to one another, and (f) is the fault core from the well 19-34 showing an altered reservoir quality. 
Table 1. The properties data from drill cores in Tanan Depression.

\begin{tabular}{ccccc}
\hline Well & Sample Depth/m & Distance to Fault $/ \mathbf{m}$ & Porosity/\% & Permeability/mD \\
\hline $19-34$ & $1540-1761$ & 179 & $4.2-27.4$ & $0.02-4093$ \\
$19-40$ & $1635-1662$ & 100 & $6.1-27.1$ & $0.04-168$ \\
$19-3$ & $2396-2420$ & 148 & $6-20$ & $0.01-450$ \\
$19-24$ & $1944-2068$ & 209 & $7.6-24.3$ & $0.03-6.81$ \\
$19-25$ & $2064-2070$ & 225 & $1.3-25.1$ & $0.01-715.6$ \\
$19-30$ & $2036-2051$ & 225 & $4.4-25.3$ & $0.03-2681$ \\
$19-35$ & $2167-2170$ & 320 & $12.7-18.3$ & $0.17-9.77$ \\
$19-45$ & $1830-2068$ & 219 & $5.9-21.3$ & $0.03-61.4$ \\
$19-65$ & $1956-2093$ & 200 & $9.7-23.2$ & $0.1-255$ \\
$19-67$ & $1609-1616$ & 84 & $16.6-23.5$ & $0.43-1221$ \\
$19-69$ & $2072-2168$ & 106 & $3.7-19.7$ & $0.85-14$ \\
$19-94$ & $2485-2491$ & 2873 & $4-9.3$ & $0.01-0.2$ \\
$19-13-1$ & $2174-2196$ & 991 & $6.5-12.7$ & $0.03-0.17$ \\
$19-26$ & $2556-2563$ & 654 & $5.6-9.5$ & $0.02-0.11$ \\
$19-29$ & $2136-2346$ & 900 & $2.7-17.6$ & $0.01-148$ \\
$19-48$ & $1968-1985$ & 1575 & $3-11.3$ & $0.01-0.17$ \\
$19-55$ & $2787-2821$ & 1195 & $1.6-10.5$ & $0.01-0.37$ \\
$19-56$ & $2559-2817$ & 1537 & $2-10.2$ & $0.01-1.09$ \\
\hline
\end{tabular}

\subsection{Influenced Range of Fractures in Low Porosity Reservoirs}

Based on earlier discussion, we concluded that faults in low porosity rocks are mainly causing brittle deformation and forming a high permeability fault zone $[4,54,60,67]$. During the formation of faults, the damaged zone develops numerous fractures intersecting the host rocks during the formation of faults. The uncemented fractures in the damaged zone have a positive impact on properties that promote hydrocarbon accumulation and migration.

In the passive rifting stage of the Tanan Depression, a large number of faults developed in the first member of the Nantun Formation. Exploration results illustrate that the distribution of oil and gas accumulations are controlled by faults placement. Based on our theoretical analysis and mathematical approach, we know that the oil-bearing properties of the reservoirs are related to the distance between well and the fault, due to the transformation of the reservoir by the fault. In order to confirm the relevance of our conclusion and evaluate the limit of the reservoir affected by a fault and its associated fractures, we counted the proportion of first member of Nantun Formation with the preponderance porosity and the distance from wells to faults about the 49 wells in the study area.

In this process, preponderance porosity is obtained by comparing the measured properties from two types of single-well reservoirs, and it can be seen that the porosity of wells adjacent to the fault are generally greater than $10 \%$, while the wells far from the faults are generally less than $10 \%$. So it was argued that $10 \%$ is the lowest limit of the preponderance porosity for hydrocarbon production (Figure $6 \mathrm{a}, \mathrm{b}$ ). The oil and gas production probability is controlled by the proportion of reservoirs in rocks with the preponderance porosity, where statistical analysis shows that the proportion of wells with the preponderance porosity decreased with increasing the distances from wells to faults. We determined an effective critical distance of about $571 \mathrm{~m}$ for reservoir positive influence by the fault zone. When the distance from the well to the fault is less than $571 \mathrm{~m}$, the proportion with the preponderance porosity (greater than 10\%) is more than $36.3 \%$ and the reservoirs are mostly economically producing. The fractures effectively improved the reservoir properties and provided advantageous conditions for hydrocarbon economic accumulation. When the distance is larger than $571 \mathrm{~m}$, the fractures have little effect on the reservoirs, which are almost water producing or a large water-oil ratio making then uneconomic (Figure 7). This phenomenon qualitatively indicates that the fracture connectivity in reservoirs near faults is better, and the fracture connectivity decreases with increasing distance from the fault. 


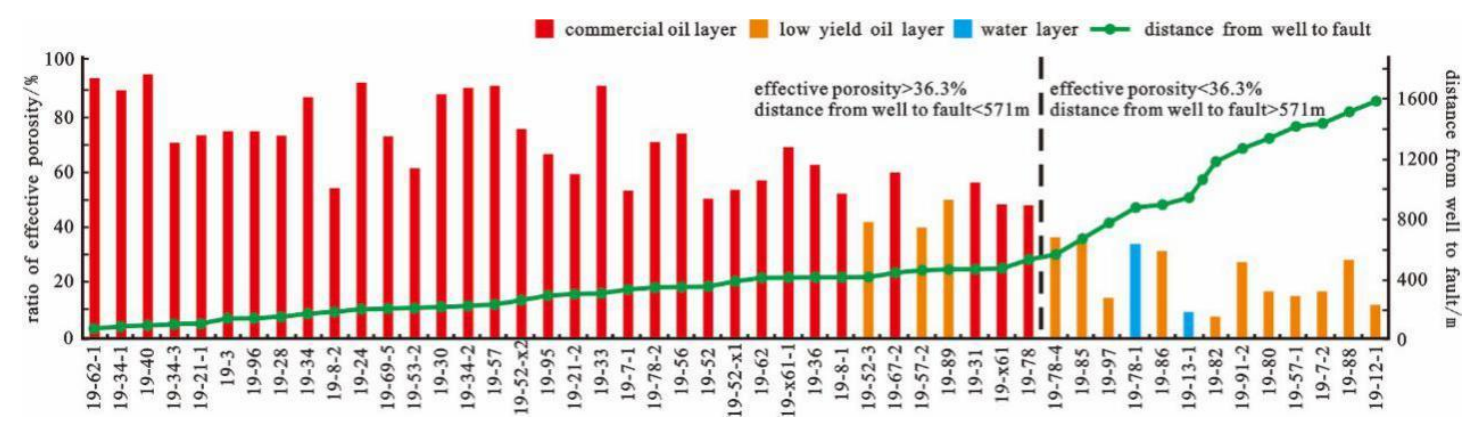

Figure 7. The relationship between the preponderance porosity of the reservoirs and the distance from a well to a fault for 49 wells in the Tanan Depression.

Based on core observations, most of the fractures are present in fault zones. We calculated the fracture density of the drill cores and the distance from wells to faults, while fracture density becomes unchanged around $500 \mathrm{~m}$ (Figure 8). The width of the damaged zone is typically affected by the scale of faults, which includes laterally extended length and throw of the main fault plane. Previous studies show a relationship between the amount of accumulated fault slip and the thickness of the core zone $[68,69]$. Due to the abnormal properties and fracture density, the effective range of reservoir alteration determined might be equivalent to the width of the fault damaged zone. However, this method is based on a statistical approach, and it may contain errors due to data limitations and uncertainties. The extent of the reservoir that is altered by faulting is not completely due to the faults, and other important components such as the palaeo-environment (pressure and temperature), tectonic activity and strata lithology, can cause the actual width of the damaged zone to be less than $571 \mathrm{~m}$. In addition, the lithology of the Nantun reservoirs is dominated by lithic sandstones and lithicarkosic sandstones, and its composition, structure, and maturity are low. The reservoir's interstitial material is mainly carbonate and mud with authigenic clay minerals (kaolinite, chlorite, etc.). A truncated unconformity has developed at the top of the Nantun formation because of multi-stage tectonic activity in the depression. During the depressions' geologic evolution, the sedimentary strata were exposed to the surface due to crustal activity, causing deposition to be interrupted and the exposed strata to be eroded. Atmospheric water infiltration along the unconformity and fractures caused the feldspar, clay minerals, and carbonate cements to dissolve forming the secondary pores and improving the properties of the reservoirs (Figure 9). Furthermore, the overpressure in reservoirs may make the fractures occur periodically to be open or closed, which can further impact the properties of reservoir. Thus, the overall improvement of the properties of the reservoir is due to the interaction of the fractures and atmospheric water leaching as well.

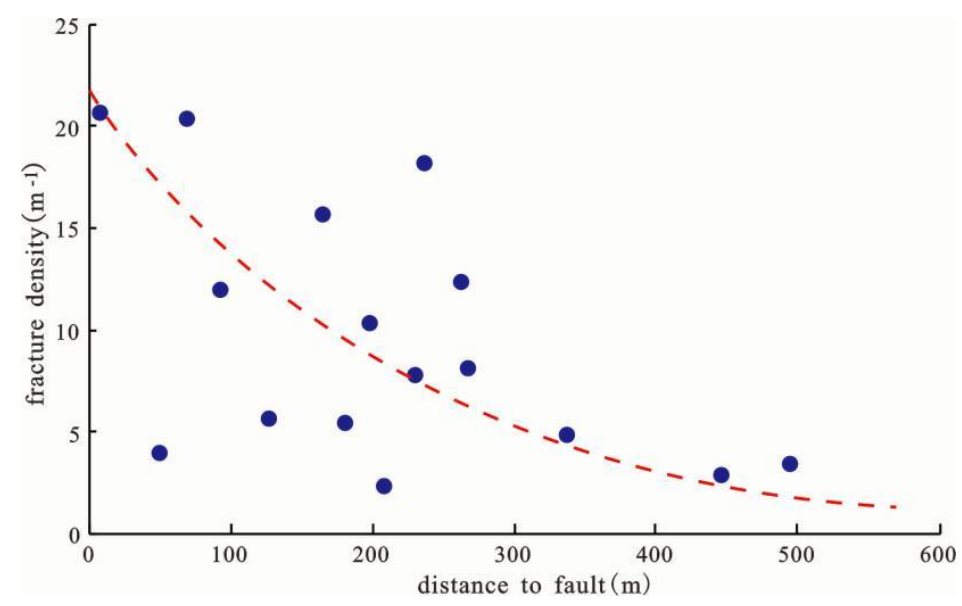

Figure 8. Relationship between fracture density and distance to fault. 


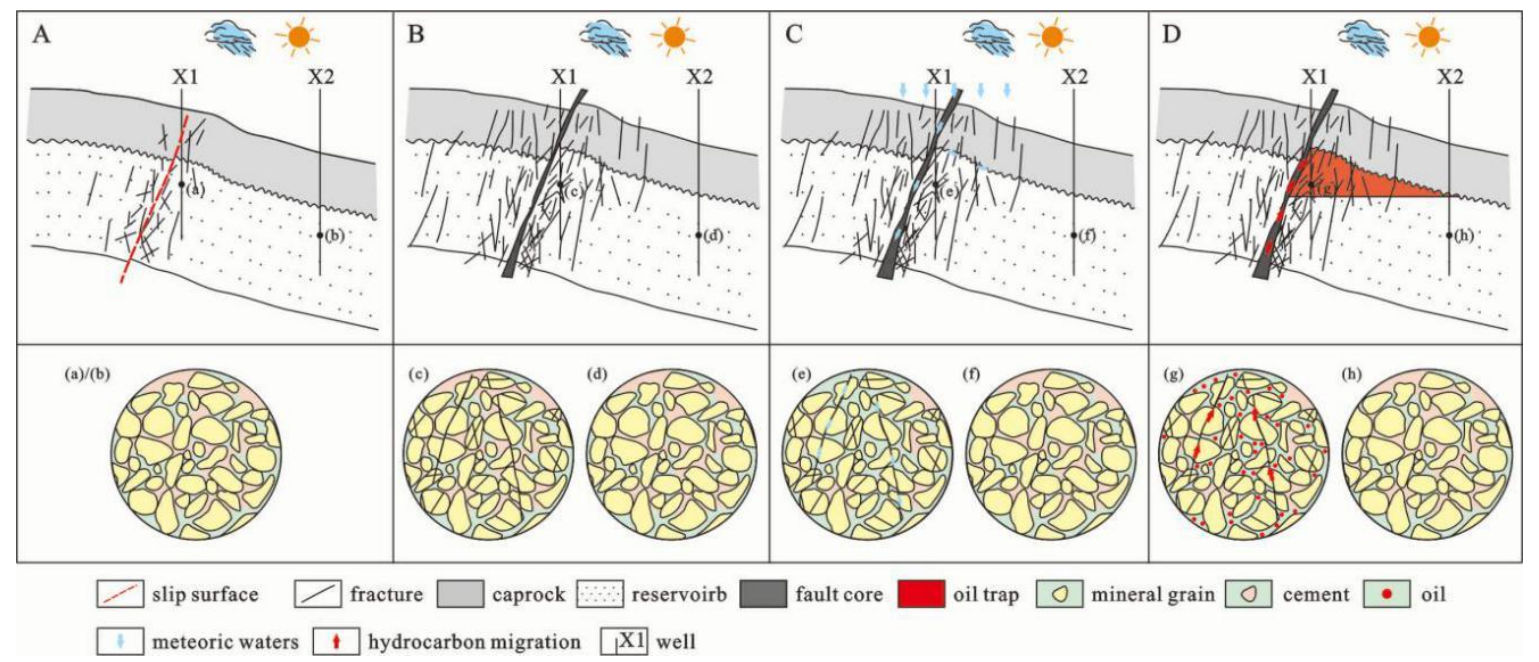

Figure 9. The transformation mode of atmospheric water leaching along faults into the reservoirs. (A) at the beginning of the fault formation process; (B) a larger number of fractures have formed in damage zones and cross cutting the grains and enhanced the permeability of reservoirs; (C) the atmospheric water inject the reservoirs along the unconformable surface, fault and fractures, and dissolve the cementation to enhance the preponderance porosity for hydrocarbon; (D) the hydrocarbon migrate along fault and fractures and accumulate in porosities. (a-h) are the microscopic pattern of reservoirs.

\section{Conclusions}

Faults in low porosity rocks mainly cause brittle deformation and result in the formation of high permeability fault zones. A large number of fractures is expected to develop in the damaged zone during fault development and effectively improve the reservoir properties compared to the host rocks. Based on previous studies and field observations in Hulunbeier City and fault cores, we concluded that the fracture density decreases with increasing distance from the fault core. According to the distribution of the faults and fractures in the damaged zone, we used a mathematical model to simulate the effect of the faults and fractures on fluid flow. The mathematical model indicated that the faults and associated fractures enhanced fluid flow efficiency when the permeability of the fractures is two orders of magnitude higher than the host rocks. By analyzing the reservoir properties and the hydrocarbon bearing probability in 49 wells in the Nantun Formation, we determined that the effective alteration extent of a fault is $571 \mathrm{~m}$. This effective alteration extent may not be only due to the damaged zone and fault activity. We proposed that the palaeo-thermal pressure of the environment and the palaeo-atmospheric water composition may affect the damaged zone as well. In this case, the fractures within a damaged zone that encompasses a reservoir are believed to enhance the productivity of the wells.

Author Contributions: R.J. and B.L. conceived and wrote the paper draft. L.G. performed the calculation. Z.L. contributed to the mathematical model and analysis of the results. X.F. discussed the results and revised the paper.

Funding: This study was financially supported by the National Natural Science Foundation of China (U1562214), the National Science and Technology Major Projects (2016ZX05024005006), the University Nursing Program for Young Scholars with Creative Talents in Heilongjiang Province (UNPYSCT-2015077), Northeast Petroleum University Excellent Research Talent Cultivation Fund-Province Innovation Reserve Talents (No. 2017-KYYWF-0063) and Northeast Petroleum University National Science Foundation for Young Scholars (2019QNL-18).

Acknowledgments: We are grateful to the Editors and two reviewers for their suggestions and comments, which significanlty improved the quality of the manuscript.

Conflicts of Interest: The authors declare no conflict of interest. 


\section{References}

1. Billings, M.P. Structural Geology, 3rd. ed.; Prentice-Hall, Inc.: Englewood Cliffs, NJ, USA, 1972; 606p.

2. Hobbs, B.E.; Means, W.D.; Williams, P.F. An Outline of Structural Geology; Wiley: Hoboken, NJ, USA, 1976; 571p.

3. Faulkner, D.; Lewis, A.; Rutter, E.; Rutter, E. On the internal structure and mechanics of large strike-slip fault zones: Field observations of the Carboneras fault in southeastern Spain. Tectonophysics 2003, 367, 235-251. [CrossRef]

4. Fossen, H.; Schultz, R.A.; Shipton, Z.K.; Mair, K. Deformation bands in sandstone: A review. J. Geol. Soc. 2007, 164, 755-769. [CrossRef]

5. Caine, J.S.; Evans, J.P.; Forster, C.B. Fault zone architecture and permeability structure. Geology 1996, 24, 1025. [CrossRef]

6. Wibberley, C.A.J.; Yielding, G.; Di Toro, G. Recent advances in the understanding of fault zone internal structure: A review. Geol. Soc. Lond. Spéc. Publ. 2008, 299, 5-33. [CrossRef]

7. Fu, X.F.; Shang, X.Y.; Meng, L.D. Internal structure of fault zone and oil/gas reservoir in low-porosity rock. J. Cent. South Univ. 2013, 44, 2428-2438.

8. Sibson, R.H. Fault rocks and fault mechanisms. J. Geol. Soc. 1977, 133, 191-213. [CrossRef]

9. Weber, K.; Mandl, G.; Pilaar, W.; Lehner, B.; Precious, R. The role of faults in hydrocarbon migration and trapping in Nigerian growth fault structures. In Proceedings of the Offshore Technology Conference, Houston, TX, USA, 8-11 May 1978.

10. Anderson, J.L.; Osborne, R.H.; Palmer, D.F. Cataclastic rocks of the San Gabriel fault-An expression of deformation at deeper crustal levels in the San Andreas fault zone. Tectonophysics 1983, 98, 209247-240251. [CrossRef]

11. Chester, F.M.; Logan, J.M. Implications for mechanical properties of brittle faults from observations of the Punchbowl fault zone, California. Pure Appl. Geophys. 1986, 124, 79-106. [CrossRef]

12. Caine, J.S.; Bruhn, R.L.; Forster, C.B. Internal structure, fault rocks, and inferences regarding deformation, fluid flow, and mineralization in the seismogenic Stillwater normal fault, Dixie Valley, Nevada. J. Struct. Geol. 2010, 32, 1576-1589. [CrossRef]

13. Dunn, D.E.; LaFountain, L.J.; Jackson, R.E. Porosity dependence and mechanism of brittle fracture in sandstones. J. Geophys. Res. 1973, 78, 2403-2417. [CrossRef]

14. Aydin, A. Small Faults Formed as Deformation Bands in Sandstone. Rock Frict. Earthq. Predict. 1978, 116, 913-930.

15. Pittman, E.D. Effect of Fault-Related Granulation on Porosity and Permeability of Quartz Sandstones, Simpson Group (Ordovician), Oklahoma. AAPG Bull. 1981, 65, 2381-2387.

16. Gabrielsen, R.H.; Koestler, A.G. Description and structural implications of fractures in late Jurassic sandstones of the Troll Field, Northern North Sea. Nor. Geol. Tidsskr. 1987, 7, 1-381.

17. Antonellini, M.; Aydin, A. Effect of faulting on fluid flow in porous sandstones: Petrophysical properties. AAPG Bull. 1994, 78, 355-377.

18. Manzocchi, T.; Ringrose, P.S. Underhill J R. Flow through fault systems in high-porosity sandstones. Geological Society, London. Spec. Publ. 1998, 127, 65-82. [CrossRef]

19. Olsson, W.A. Origin of Lüders' bands in deformed rock. J. Geophys. Res. Space Phys. 2000, 105, 5931-5938. [CrossRef]

20. Fisher, Q.; Knipe, R. The permeability of faults within siliciclastic petroleum reservoirs of the North Sea and Norwegian Continental Shelf. Mar. Pet. Geol. 2001, 18, 1063-1081. [CrossRef]

21. Schueller, S.; Braathen, A.; Fossen, H.; Tveranger, J. Characterization of extensional fault damage zones and deformation band populations based on outcrop data in porous sandstones. J. Struct. Geol. 2013, 52, 148-162. [CrossRef]

22. Gudmundsson, A.; Simmenes, T.H.; Larsen, B.; Philipp, S.L. Effects of internal structure and local stresses on fracture propagation, deflection, and arrest in fault zones. J. Struct. Geol. 2010, 32, 1643-1655. [CrossRef]

23. Gong, L.; Gao, S.; Wu, J.P.; Fu, X.F.; Chen, S.M.; Gao, A.; Yao, J.Q. Natural gas accumulation and fractures in volcanic rocks of Yingcheng Formation in Xujiaweizi Fault Depression. Geotectonica et Metallogenia 2017, 41, 283-290.

24. Jamison, W.R.; Stearns, D.W. Tectonic deformation of Wingate Sandstone, Colorado National Monument. AAPG Bull. 1982, 66, 2584-2608. 
25. Knipe, R.; Fisher, Q.; Jones, G.; Clennell, M.; Farmer, A.; Harrison, A.; Kidd, B.; McAllister, E.; Porter, J.; White, E. Fault seal analysis: Successful methodologies, application and future directions. Nor. Pet. Soc. Spéc. Publ. 1997, 7, 15-38.

26. Gibson, R.G. Physical character and fluid-flow properties of sandstone-derived fault zones. Geol. Soc. Lond. Spéc. Publ. 1998, 127, 83-97. [CrossRef]

27. Heynekamp, M.R.; Goodwin, L.B.; Mozley, P.S.; Haneberg, W.C.; Moore, J.C. Controls on fault-zone architecture in poorly lithified sediments, Rio Grande Rift, New Mexico: Implications for fault-zone permeability and fluid flow. Auror. Phenomenol. Magnetos. Process. Earth Other Planets 1999, 113, 27-49.

28. Hesthammer, J.; Fossen, H. Uncertainties associated with fault sealing analysis. Pet. Geosci. 2000, 6, 37-45. [CrossRef]

29. Taylor, W.L.; Pollard, D.D. Estimation of in situ permeability of deformation bands in porous sandstone, Valley of Fire, Nevada. Water Resour. Res. 2000, 36, 2595-2606. [CrossRef]

30. Lothe, A.E.; Gabrielsen, R.H.; Hagen, N.B.; Larsen, B.T. An experimental study of the texture of deformation bands: Effects on the porosity and permeability of sandstones. Pet. Geosci. 2002, 8, 195-207. [CrossRef]

31. Shipton, Z.K.; Evans, J.P.; Robeson, K.R.; Forster, C.B.; Snelgrove, S. Structural heterogeneity and permeability in faulted eolian sandstone: Implications for subsurface modeling of faults. AAPG Bull. 2002, 86, 863-883.

32. Scholz, C.H.; Anders, M.H. The permeability of faults. Mech. Involv. Fluid. Faulting 1994, 94, 247-253.

33. Goddard, J.V.; Evans, J.P. Chemical changes and fluid-rock interaction in faults of crystalline thrust sheets, northwestern Wyoming, USA. J. Struct. Geol. 1995, 17, 533-547. [CrossRef]

34. Crawford, B.R. Experimental fault sealing: Shear band permeability dependency on cataclastic fault gouge characteristics. Geol. Soc. Lond. Spéc. Publ. 1998, 127, 27-47. [CrossRef]

35. Robertson, E.C. Relationship of fault displacement to gouge and breccia thickness. Min. Eng. 1983, 35, 1426-1432.

36. Hull, J. Thickness-displacement relationships for deformation zones. J. Struct. Geol. 1988, 10, 431-435. [CrossRef]

37. Marrett, R.; Allmendinger, R.W. Kinematic analysis of fault-slip data. J. Struct. Geol. 1990, 12, $973-986$. [CrossRef]

38. Robertson, E.C. Continuous formation of gouge and breccia during fault displacement. In The 23rd US Symposium on Rock Mechanics (USRMS); American Rock Mechanics Association: Alexandria, Virginia, USA, 1982.

39. Aviles, C.A.; Scholz, C.H.; Boatwright, J. Fractal analysis applied to characteristic segments of the San Andreas Fault. J. Geophys. Res. Space Phys. 1987, 92, 331. [CrossRef]

40. Gao, G.; Li, Y.J. Structural transfer zones and its relationship of petroleum migration and accumulation of the east sub-sag in South Buir sag, Tamsag Basin. Chin. J. Geol. 2011, 46, 942-957.

41. Zhang, J.L.; Meng, Q.A.; Qi, J.F. Multi-stage structural deformation features and hydrocarbon accumulation in faulted basin: A case study in Nanbeier Sag of Hailar-Tamtsag Basin. Pet. Geol. Exp. 2012, 34, 368-375.

42. Sun, Y.H.; Shi, P.P.; Yang, F.; Yuan, H.Q.; Yang, M. Analysis on tectonic evolution and genetic mechanism of oil-rich structural belt at middle fault depression belt in Hailar-Tamtsag Basin. Chin. J. Geol. 2012, 47, 700-713.

43. Liu, S.J. Analysis of the controlling factors and characteristic of reservoirs in Nantun Formation, Tanan Depression. Inn. Mong. Petrochem. Ind. 2010, 14, 137-141.

44. Liu, S.J.; Gao, G.; Zhu, D.F.; Wu, G.Y.; Wang, J.K.; Zhang, G.; Sun, X.D.; Liu, H.; Li, C.B.; Li, Q. Early Cretaceous fracturing and basin evolution of the south Buir Sag of Tamtsag Basin in Mongolia. Geotecton. Metallog. 2015, 39, 780-794.

45. Fu, X.F.; Chen, Z.; Yan, B.Q.; Yang, M.; Sun, Y. HAnalysis of main controlling factors for hydrocarbon accumulation in central rift zone of Hailar-Tamt sag Basin using a fault-caprock dual control model. Sci. China Earth Sci. 2013, 56, 1357-1370. [CrossRef]

46. Li, W.K.; Zhang, Y.; Fang, J.; Wang, J.; Liu, D.M. Control factors of hydrocarbon accumulation for lithologic reservoir in Beier Depression, Hailar Basin. Acta Pet. Sin. 2015, 36, 337-346.

47. Meng, Q.A.; Liu, L.; Qu, X.Y.; Wang, C.C.; Wang, X.Q. Reservoir characteristics and progresses controlling porosity in Tongbomiao-Nantun Formation from Beier Depression, China and from Tanan Depression, Mongolia. J. Jilin Univ. 2010, 40, 1232-1240. 
48. Wang, X.D.; Jia, C.Z.; Meng, Q.A.; Zhang, G. Main controlling factors of the formation and distribution of Nantun Formation lithologic reservoirs in the abrupt slope zone, Tanan Sag. Acta Pet. Sin. 2011, 32, 564-572.

49. Chen, W.C.; Qi, J.F.; Jiang, H.F.; Liu, X.; Sun, J.H.; Xin, S.W. Characteristics of fault structure in Tanan Sag, Haita Basin in Dornod Aymag, Mongolia and its hydrocarbon significance. J. Palaeogeogr. 2013, 15, 539-550.

50. Zhang, J.L. Macroscopic heterogeneity and hydrocarbon of Nantun Formation in the Eastern Structural Belt of Tanan Depression. J. Jilin Univ. 2011, 41, 351-358.

51. Fang, S.; Xie, R.X.; Miao, C.S.; Liu, Z.J.; Meng, Q.A.; Zhang, G.; Qu, Y.H.; Zhang, J.L. Reservoir types and distribution of Nantun Formation in Tanan Depression. J. Jilin Univ. 2012, 42, 8-16.

52. Fu, X.F.; Xu, P.; Wei, C.Z.; Lv, Y.F. Internal structure of normal fault zone and hydrocarbon migration and conservation. Earth Sci. Front. 2012, 19, 1-13.

53. Liu, Z.B.; Zhao, R.S.; Yan, L.; Yu, Y.H. Depositional system characteristics of the first member of the Nantun Formation in Tanan sag, the Hai-Ta Basin. Oil Gas Geol. 2013, 34, 743-750.

54. Fossen, H. Deformation bands formed during soft-sediment deformation: Observations from SE Utah. Mar. Pet. Geol. 2010, 27, 215-222. [CrossRef]

55. Du Bernard, X.; Eichhubl, P.; Aydin, A. Dilation bands: Anew form of localized failure in granular media. Geophys. Res. Lett. 2002, 29, 1-4. [CrossRef]

56. Bense, V.F.; Van den Berg, E.H.; Van Balen, R.T. Deformation mechanisms and hydraulic properties of fault zones in unconsolidated sediments; the Roer Valley Rift System, the Netherlands. Hydrogeol. J. 2003, 11, 319-332. [CrossRef]

57. Aydin, A.; Johnson, A.M. Analysis of faulting in porous sandstones. J. Struct. Geol. 1983, 5, 19-31. [CrossRef]

58. Beach, A.; Brown, J.L.; Welbon, A.I.; McCallum, J.E.; Brockbank, P.; Knott, S. Characteristics of fault zones in sandstones from NW England: Application to fault transmissibility. Geol. Soc. Lond. Spéc. Publ. 1997, 124, 315-324. [CrossRef]

59. Wibberley, C.A.; McCaig, A.M. Quantifying orthoclase and albite muscovitisation sequences in fault zones. Chem. Geol. 2000, 165, 181-196. [CrossRef]

60. Blenkinsop, T.G.; Fernandes, T.R.C. Fractal characterization of particle size distributions in chromitites from the Great Dyke, Zimbabwe. Pure Appl. Geophys. 2000, 157, 505-521. [CrossRef]

61. Liu, J.L. Flow and microstructural evolution of rocks in the upper crust: Evidence from naturally and experimentally deformed rocks. Earth Sci. Front. 2004, 11, 503-509.

62. Billi, A. Grain size distribution and thickness of breccia and gouge zones from thin $(<1 \mathrm{~m})$ strike-slip fault cores in limestone. J. Struct. Geol. 2005, 27, 1823-1837.

63. Su, J.; Zhang, S.C.; Yang, H.J.; Zhu, G.Y.; Chen, J.P.; Zhang, B. Control of fault system of formation of effective carbonate reservoir and the rules of petroleum accumulation. Acta Pet. Sin. 2010, 31, 196-203.

64. Geraud, Y.; Diraison, M.; Orellana, N. Fault zone geometry of a mature active normal fault: A potential high permeability channel (Pirgaki fault, Corinth rift, Greece). Tectonophysics 2006, 426, 61-76. [CrossRef]

65. Fossen, H.; Johansen, T.E.S.; Hesthammer, J.; Rotevatn, A. Fault interaction in porous sandstone and implications for reservoir management; examples from southern Utah. AAPG Bull. 2005, 89, 1593-1606. [CrossRef]

66. Wu, G.H.; Yue, G.L.; Shi, J.; Huang, G.J.; Hu, T.P. Analysis of connectivity of fractures of Ordovician carbonates and its implication in central Tarim Basin. West China Pet. Geosci. 2006, 2, 156-159.

67. Cook, J.E.; Dunne, W.M.; Onasch, C.M. Development of a dilatant damage zone along a thrust relay in a low-porosity quartz arenite. J. Struct. Geol. 2006, 28, 776-792. [CrossRef]

68. Micarelli, L.; Benedicto, A.; Wibberley, C. Structural evolution and permeability of normal fault zones in highly porous carbonate rocks. J. Struct. Geol. 2006, 28, 1214-1227. [CrossRef]

69. Lin, A.; Yamashita, K. Spatial variations in fault zone structures along strike-slip faults: An example from the active faults in southwest Japan. J. Struct. Geol. 2013, 57, 1-15. [CrossRef]

(C) 2019 by the authors. Licensee MDPI, Basel, Switzerland. This article is an open access article distributed under the terms and conditions of the Creative Commons Attribution (CC BY) license (http://creativecommons.org/licenses/by/4.0/). 